\title{
Cyanotoxins: A hidden cause of Chronic Kidney Disease of unknown etiology (CKDu) in Sri Lanka - A review
}

\author{
Pathmalal M Manage \\ Centre for Water Quality and Algae Research, Department of Zoology, Faculty of Applied \\ Scinces, University of Sri Jayewardenepura
}

Correspondence (pathmalal@sjp.ac.lk)

http://orcid.org/0000-0002-0465-6950

\begin{abstract}
CKDu has been identified as a major public health issue in countries such as Sri Lanka, India and Nicaragua, which causes significant deaths per year. Significant similarities have been observed among these endemic nephropathies regardless of their geographical separation. Existing evidence favors a multi-factorial etiology, but research over the last few decades has failed to recognize the specific risk factors. Based on the geographical distribution that is unique and evidence of histopathological nature, it is speculated that $\mathrm{CKDu}$ is environmentally induced health problem. Hypothesis linking acetylcholinesterase (AChE) inhibiting organophosphate pesticides, metal-chelating glyophosate, agrochemicals, cadmium, arsenic, fluoride, hardness, and algae/cyanobacteria are considered as important factors in the etiology of CKDu. However, to date, no single geochemical parameter is shown to be directly related to the CKD etiology on the basis of the elements determined during research studies, and it is very likely that the unique hydrogeochemistry and microbiology of the drinking water is closely associated with the incidence of the disease in the endemic areas. The paper discuss understudied area of research is whether cyanotoxin formation from algal blooms may be a risk factor that contributes to CKDu in Sri Lanka as cyanotoxins in $\mathrm{CKDu}$ has been considered but not investigated.
\end{abstract}

Key words: cyanobacteria, cyanotoxins, environmental exposure, cell culture studies, cyto toxicity

\section{INTRODUCTION}

Chronic Kidney Disease (CKD) is a global health problem and it identified as the $7^{\text {th }}$ most common cause of death according to WHO (2012). The number of patients with CKD unknown etiology $(\mathrm{CKDu})$ in Sri Lanka have increased alarmingly over recent decades in the dry zone of rural farming communities leading to national concern and urgent need for action as CKDu is a leading non-communicable disease, and cause of death (Eckardt et al. 2009). Existing evidence favors a multi-factorial etiology, but research over the last few decades has failed to recognize the specific risk factors. In research conducted to date, significant effort has been made to characterize $\mathrm{CKDu}$ in each of the endemic areas independently and through developing regionspecific hypotheses for the root causes using selected geographies. Theses hypotheses attributed $\mathrm{CKDu}$ to several environmental, genetic, behavioral, or occupational factors. Thus, causative factors and etiology of this chronic kidney disease is still considered uncertain or unknown and abbreviated as Chronic Kidney Disease of unknown etiology $(\mathrm{CKDu})$.

\section{The Sri Lankan Context of CKDu}

Chronic Kidney Disease of unknown etiology $(\mathrm{CKDu})$ has emerged as a significant contributor to the burden of chronic diseases in rural parts of Sri Lanka during the last three decades (Wanigasuriya 2012). CKDu is considered as a new form of chronic kidney disease which cannot be attributed to hypertension, diabetes, chronic glomerulonephritis or other known etiologies. The disease is slowly progressive, irreversible, and asymptomatic until late stages (Athuraliya et al. 2009). The disease burden is most prominent in the North Central Province (NCP) of Sri Lanka and has extended to two adjacent provinces namely, the Uva and the North Western Provinces (NWP). The community prevalence of CKDu in the NCP was reported as $16.9 \%$ in women and $12.9 \%$ in men, but the severe stages were seen more frequently in men (Jayatilake et al. 2013). Renal biopsies of $\mathrm{CKDu}$ patients have demonstrated a tubulointestitial damage suggestive of a toxic induced renal damage (Wijetunge et al. 2013). Currently in excess of more than 11,000 CKDu patients are receiving treatment and since 2010, there has been extensive research funded by the 
Pathmalal M Manage

national and international agencies including the World Health Organization (WHO), to determine population prevalence, risk factors, treatment strategies and socioeconomic impact (Wimalawansa 2016).

Based on the geographical distribution that is unique and evidence of histopathological nature, it is speculated that $\mathrm{CKDu}$ is environmentally induced health problem (Wanigasuriya 2012). Two studies have assessed the presence of nephrotoxic mycotoxins, including ochratoxin A, in food and biological samples obtained from $\mathrm{CKDu}$ patients in the region and Japanese controls (Wanigasuriya 2012; Desalegn 2011). Association between potential exposure to acetylcholinesterase (AChE) inhibiting organophosphate pesticides with CKDu has been explored (Wanigasuriya et al. 2007) and a hypothesis linking metal-chelating glyophosate with CKDu has been put forward (Jayasumana et al. 2014). A WHO study showed significantly higher urinary excretion of cadmium in individuals with $\mathrm{CKDu}$, and the dose-effect relationship between urine cadmium concentration and CKDu stages (Jayatilake et al. 2013). These findings suggest that cadmium exposure is a risk factor for the pathogensis of $\mathrm{CKDu}$. Chronic exposure of people in the endemic area to low levels of cadmium was suggested to be through the food chain and exposure to pesticide. However, CKD patients from Sri Lanka do not show any indication of long-standing cadmium exposure (Piyathilaka et al. 2015). Therefore, it is questionable to consider cadmium as the root cause for CKD in Sri Lanka.

Although evidence has emerged that drinking water may play a major role in the etiology of the disease, because CKDu occurs exclusively in settlements where groundwater is the main source of drinking water (Chandrajith et al. 2011) and it is more common among members of lower socio-economic strata, particularly the farmers (Athuraliya et al. 2009). Studies conducted so far have demonstrated nephrotoxic heavy metals including cadmium and arsenic not exceeding the WHO stipulated limits (Jayatilake et al. 2013; Wimalawansa 2016). It has been reported that fluoride levels in water consumed by CKDu patients in affected areas are above the limit recommended for tropical countries by the WHO (James et al. 2010). Wimalawansa (2016) documented that hydro-geochemistry of the $\mathrm{CKDu}$ affected areas are inundated with high levels of iron, fluoride, manganese, sodium, magnesium, and calcium levels in drinking water, which exceeds the standards of drinking water provided by the Sri Lanka Standard Institute (SLSI) and WHO. It is postulated that synergistic effect of fluoride and hardness of water is an important factor in the etiology of CKDu (Chandrajith et al. 2011; Wasana et al. 2017). Although no single geochemical parameter is shown to be directly related to the CKD etiology on the basis of the elements determined during research studies, it is very likely that the unique hydrogeochemistry of the drinking water and microbial toxins are closely associated with the incidence of the disease in the endemic areas.

Despite the presence of natural toxins including cynatoxins that causes $\mathrm{CKDu}$ being considered in research, they have not been adequately examined. One understudied area of research is whether cyanotoxin contaminated water is a risk factor that contributes to $\mathrm{CKDu}$ in Sri Lanka.

\section{Cyanobacteria and Cyanotoxins}

Global occurrences of cyanobacteria blooms in aquatic systems have increased over recent decades due to anthropogenic eutrophication (Manage et al. 2009; Paerl and Huisman 2008). In recent research studies conducted by the researcher identified cyanobacteria in $75 \%$ of freshwater bodies tested in CKDu endemic areas compared to $40 \%$ of freshwater bodies in CKDu non-endemic areas. Recent findings also reveal toxin-producing cyanobacteria (Microcytis aeruginosa, Cylindrospermopsis sp. and Anabaena sp.) in majority of drinking water reservoirs (Sethunga and Manage 2010). Additionally, surface and dug well water in CKDu-endemic areas significantly correlate between cell density of cyanobacteria and cyanotoxins (Manage et al. 2009). Many of the blooms are highly toxic, presenting a serious hazard to human and animal health. The most commonly occurring cyanotoxins are the peptide hepatotoxins; microcystins (MCs) and nodularins which are produced by many species of cyanobacteria (Idroos and Manage 2015; Manage et al. 2009). Cyanotoxins; microcystin (MCs), nodularin (NOD), and Cylindrospermorpsin (CYL) can result in severe progressive damage to organs such as liver and kidneys (nephrotoxins) following chronic exposure (Piyathilaka et al. 2015). It has been documented that human exposure to toxins produced by freshwater 
cyanobacteria (blue green algae) maybe a possible cause of the emerging renal disease (Piyathilaka et al. 2015).

Jochimsen et al. (1998) indicate that except for the Brazil outbreak, there is a dearth of reliable statistics on the causalities of humans, aquatic and wild animals and birds due to toxins formed and blooms pertaining to cyanobacterial growth.

Contact of contaminated water with MCs through swimming, bathing, swallowing or airborne droplets generated from nearby contaminated ponds or reservoirs could cause adverse health effects (Lawton et al. 1999). In addition, they are often present in the environment long after the cyanobacterial bloom has lysed (Manage et al. 1999, 2010; Sethunga and Manage 2010; Idroos et al. 2014). The occurrence of MCs are a serious health hazard and acute doses have been responsible for illness and fatalities in animals and humans which led the WHO to set a guideline limit of $1 \mu \mathrm{g} / \mathrm{L}$ microcystin-LR (MC-LR) as the maximum allowable concentration in drinking water (WHO 1998). Moreover, chronic exposure has been associated with primary liver cancer in epidemiological studies (Fisher and Dietrich 2000). Manage et al. (2009) recorded that the hepatotoxic effect of the Microcystis aeruginosa on Wister rats in vitro. In 2015, Manage and his research team recorded Microcystin-LR-induced cytotoxicity and apoptosis in human embryonic kidney and human kidney adenocarcinoma cell lines (Piyathilaka et al. 2015).

MC produced by the cynobacteria has a stable chemical structure. Lawton et al. (1999) highlighted the failure of conventional water treatment processes such as coagulation, flocculation, filtration and disinfection by chlorination as well as heating up to $100^{\circ} \mathrm{C}$, in removing cyanotoxins from drinking water that comply with the WHO drinking water standards. Therefore, cyanotoxins have created a major challenge on conventional water treatment facilities. Thus, Manage (2012) highlighted that provision of uncontaminated drinking water is a vital factor to safeguard health of consumers in the long term. Given the increasing occurrence of toxigenic cyanobacteria surface and ground water in Sri Lanka, along with the increasing cases of $\mathrm{CKDu}$, with no associated risk factor, there is a clear need to investigate any correlation between these. Cyanobacteria produce a supreme array of bioactive secondary metabolites, including alkaloids, polyketides and nonribosomal peptides considered as cyanotoxins (Nogueira et al. 2006). The toxic secondary metabolic compounds produced by cyanobacteria can affect organisms by causing health hazards to livestock and wildlife and even human intoxications have been documented (Giaramida et al. 2013). In addition, absorption of cyanotoxins via the root system of crops has also been recorded (Wijewickrama and Manage 2017).

\section{Toxins producing cyanobacteria}

In addition to cell wall LPS endotoxins, research has indicated that there are few genera of cyanobacteria (out of more than 150) that could produce toxins. Further, it also has been discovered that production of toxins and the toxicity varies highly both within and between blooms and based on the time durations of a selected bloom. Secondary metabolites of cyanotoxins cause organ and tissue failures with the collapse of physiological system (Nogueira et al. 2006), is elaborated in Table 1.

\section{Human exposure of cyanotoxins via food intake}

Several routes of human exposure to cyanotoxins via food intake are: chronic and accidental ingestion of contaminated drinking water (Sethunga and Manage 2010); consumption of contaminated vegetables and fruits irrigated with water containing cyanotoxins; consumption of freshwater fish, shellfish, etc. (Abeysiri and Manage 2017; Wijerathne and Manage 2018) and edible plants (Wijewickrama and Manage 2017) from contaminated waters; oral intake of cyanobacterial dietary supplements (if cyanotoxin levels are not controlled) and rice (Abeysiri, Wanigasuriya and Manage 2018a) where toxin has bio accumulated in tissues. Such diverse modes of exposure present a huge epidemiological challenge. 
Pathmalal M Manage

Table 1 Common genus of cyanobacteria and toxins produced by them

\begin{tabular}{ll}
\hline Type of Cyanotoxin & Responsible Cyanobacteria \\
\hline Neurotoxin & \\
Anatoxin-a, & Anabaena, Aphanizomenon, Oscillatoria \\
Homoantoxin-s & Anabaena, Oscillatoria (planktothrix) \\
Anatoxin-a(s) & Anabaena, Aphanizomenon, Lygbya, cylindrospermopsis \\
Saxitoxins & \\
Hepatotoxins & Aphanizomenon, Umezakia, Cylindrospermopsis, \\
Cylindrospermopsis & Anabaena, Aphanocapsa, Nostoc, Hapalosiphon, \\
Microcystins & MicrocystisOscillatoria, Planktothrix \\
Nodularins & Nodularia \\
Dermal toxins/irritants & \\
Debromoaplysiatoxin, & Lyngbya \\
Lyngbyatoxin & Schizothrix \\
Aplysiatoxin & .
\end{tabular}

Adopted and modified from Lankoff et al. (2004)

Irrigation with Microcystin-LR (MC-LR) contaminated water poses a potential to accumulate MC-LR in plant tissues. A recent study showed that the grain samples of, O. sativa variants BG358 and leafy greens I. aquatica collected from paddy fields irrigated by the Padaviya tank water were contaminated with MC-LR $(20.97 \pm 0.31 \mu \mathrm{g} / \mathrm{kg})$ and $(132.86 \pm 0.26$ $\mu \mathrm{g} / \mathrm{kg}$ ), respectively (Wijewickrama and Manage 2017). It was found that the mean concentration of MC-LR in Padaviya water ranged between 50$65 \mu \mathrm{g} / \mathrm{l}$ throughout the year. Further, high concentration of MC-LR was detected in laboratory grown, continuous Microcystis bloom exposed O. sativa, variants BG358 (567.52 \pm 4.88 $\mu \mathrm{g} / \mathrm{kg})$ and leafy green I. aquatic $(350.82 \pm 2.86$ $\mu \mathrm{g} / \mathrm{kg}$ ), respectively. The evaluated mean human health risk of the laboratory grown and field sample of O. sativa, variants BG358 was $2.84 \pm 0.01 \mu \mathrm{g} / \mathrm{kg}$ and $0.10 \pm 0.01 \mu \mathrm{g} / \mathrm{kg}$ of body weight per day, respectively. The evaluated mean human health risk via the consumption of leafy greens $I$. aquatica grown in the laboratory and for the samples collected from the field was $0.06 \pm 0.01 \mu \mathrm{g} / \mathrm{kg}$ and $0.03 \pm 0.01 \mu \mathrm{g} / \mathrm{kg}$ of body weight per day (Wijewickrama and Manage 2017). In theses studes, it was found that the estimated values of the MC-LR were exceeded the Tolerable Daily Intake (TDI) of $0.04 \mu \mathrm{g} / \mathrm{kg}$ of body weight per day by the WHO (WHO 2012) Thus, the results of the study revealed the possible bioaccumulation of MC-LR in some rice varieties and edible leafy greens. Thus, accumulation of cyanotoxin via food intake also is a significant pathway to the exposure of MCLR.

Contamination of MC-LR in vertebrates as well as in invertebrates has been addressed in recent studies (Carneiro et al. 2015; Liang et al. 2007). Around the world, there are occasions which had indicated that cichlid family, Oreochromis niloticus are considered as bio indicators. The hepatotoxic MC-LR affects the liver as the main targeting organ causing hepatocarcinoma and cellular disruptions (Jos et al. 2005). The presence and accumulation of MCs in different fish tissues have been reported by experimental and field studies. There are several reports on accumulation of $\mathrm{MCs}$ in liver (Malbrouck et al. 2003), gills (Malbrouck et al. 2003), intestine, muscle (Chen et al. 2006) and brain (Cazenave et al. 2005) of Oreochromis niloticus which is the most popular protein source in most part of the CKDu prevalence area of the country suggesting the potential of MCs accumulation via food sources.

Recent studies conducted by Wijeratne and Manage (2018) revealed that skin and flesh are the vulnerable parts of the accumulation of MCs in most of freshwater fish, suggesting that risk assessed is higher at consumption of those edible parts. Further, it has been mentioned that the balneation and ingestion are two different exposure routes of the MCs contaminations that enter the organisms' body depend on the 


\section{Pathmalal M Manage}

exposure period. These areas of research have to be addressed in detail to explain the exposure pathways of MCs in human body.

\section{Cytotoxicity assessment of MC-LR}

The cytotoxicity and possible apoptotic effects of MC-LR on human embryonic kidney cell line (HEK-293) and human kidney adenocarcinoma cell line $(\mathrm{ACHN})$ were evaluated by Piyathilaka et al. (2015), who exposed cells for $24 \mathrm{hrs}$ to pure MC-LR (1.0-200 mM). The effect of MCLR on kidney cells were evaluated using 3-(4,5dimethylthiazol-2-yl)-2,5-diphenyltetrazolium bromide (MTT) and sulphorhodamine B (SRB) cell viability assays. It was detected that all the toxins had a significantly higher cytotoxicity on normal kidney cells than on the kidney adenocarcinoma cells. Cell viability in both cell lines was significantly decreased after treatment with MC-LR at $50 \mathrm{mM}$ for $24 \mathrm{hrs}(\mathrm{p}<0.001$, One-
Way ANOVA). Furthermore, MC-LR had the lowest $\mathrm{IC}_{50}$ values while MC-LW had the highest $\mathrm{IC}_{50}$ values. Therefore, Piyathilaka et al. (2015) demonstrated that cyanotoxins could cause cytotoxic effects on kidney cells and the effect of MC-LR was greatest while MC-LW was least toxic cyanotoxin on both cell types tested. Other cyatotoxins; MC-RR, MC-LF and Nodularin showed moderate cytotoxicity on human renal cells.

Further, using a One-Way ANOVA analysis, it was observed that cytotoxic effect of MC-LR on HEK-293 and ACHN cells were significant ( $p<0.001$ ), which was assessed by SRB and MTT assays. The evaluated toxic effect showed dose dependent cytotoxicity in both cell lines (Figure 1). Compared to ACHN cells, HEK-293 cells showed a significantly $(\mathrm{p}<0.001)$ lower $\mathrm{IC}_{50}$ under the MTT assay (Figure 2). However, the SRB assay indicated higher values for HEK-293 cells.
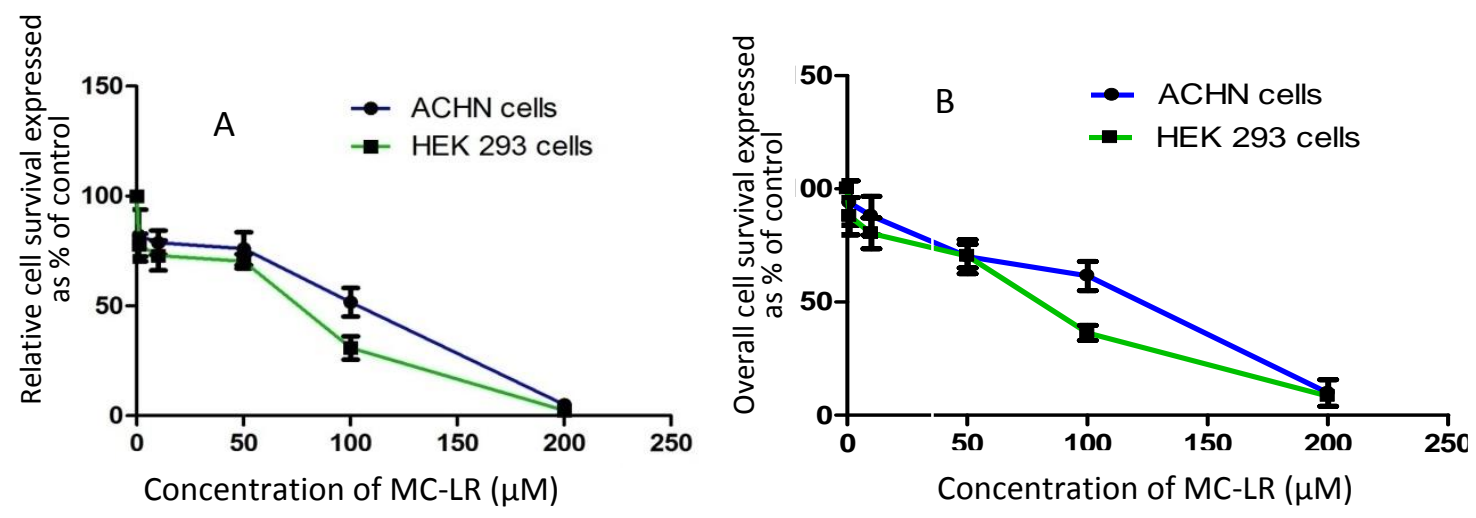

Fig 1 Comparative dose dependent cytotoxicity of MC-LR on HEK-293 (A) and ACHN (B) cell lines (Source: Piyathilaka et al. 2015)

MTT (3-(4,5-dimethylthiazol-2-yl)-2,5diphenyltetrazolium bromide) and SRB (Sulphorhodamine B) assays revealed a significant decrease in cell viability in both cell lines after treatment with MC-LR at $50 \mu \mathrm{M}$ for $24 \mathrm{~h}(\mathrm{p}<0.001)$. Moreover, MC-LR treated ACHN and HEK-293 cells exhibited a marked dose dependent loss of confluence as judged by phase contrast microscopy. Thus, the study provides direct evidence that MC-LR exposure can induce apoptosis related morphological changes, up regulation of the expression of $B a x$ and p53 genes modulate expression of Survivin gene and increase activity of caspase 3 and 9 in Human embryonic Kidney (HEK-293) and Human kidney adenocarcinoma (ACHN) cells. Hence, Bax, p53, Survivin, caspase 3 and 9 are most likely to be involved in MC-LR induced cellular damage. Moreover, this study contributes to elucidate the toxicological mechanism underlying the effects of MC-LR on human kidneys (Piyathilaka et al. 2015). 
Pathmalal M Manage

Cytotoxicity assessment of cyanobacterial crude extract
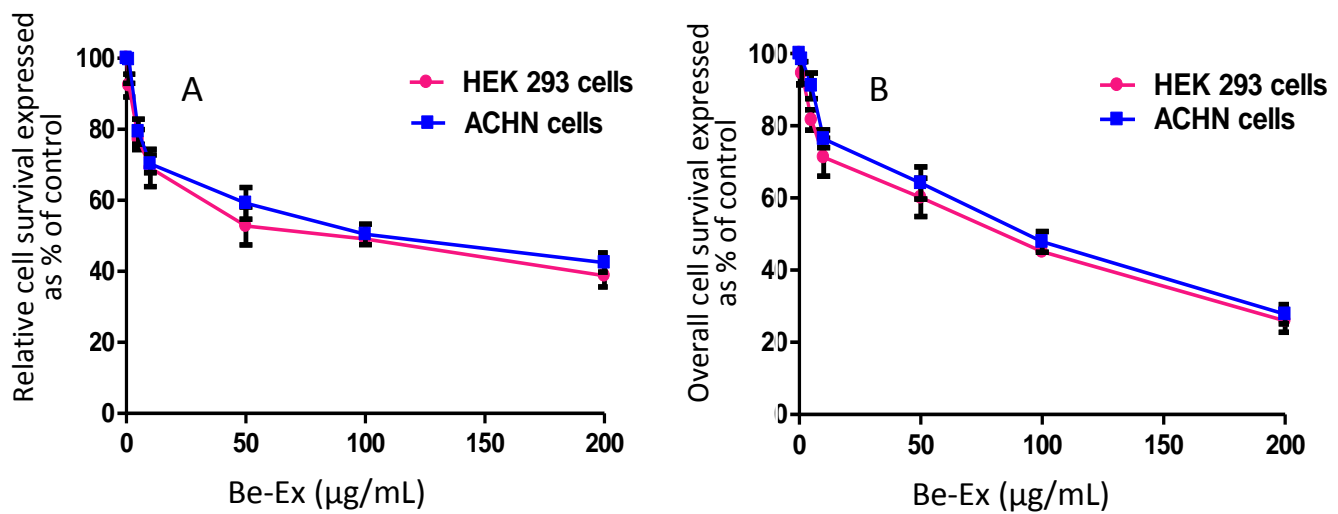

Fig 2 Viability of ACHN and HEK-293 cells exposed to different concentrations of cyanobacterial crude extract for $24 \mathrm{hrs}$ assessed by SRB assay [A] and MTT assay [B]. Results are expressed as the mean percentage of three replicates relative to control \pm standard deviation $(p<0.001)$ (Source: Piyathilaka et al. 2015)

Detection of Microcystin-LR (MC-LR) and Cylindrospermopsin (CYN) in Human urine

Measurements of MC-LR and CYN concentrations of urine can help in monitoring recent or long-term exposures through ingestion via drinking water sources (Greer et al. 2018). The occurrence of multiple cyanobacteria with elevated cyanotoxin concentrations CYN (1.0 \pm
0.01 to $\left.5.3 \pm 0.02 \mu \mathrm{gL}^{-1}\right)$ and MC-LR $(1.0 \pm 0.01$ to $\left.7.6 \pm 0.34 \mu \mathrm{gL}^{-1}\right)$ ] in commonly used dug wells show that ingestion of well water is a likely source of cyanotoxin exposure. Indeed, our ongoing study revealed a high concentration of CYN $\left(100 \pm 10\right.$ to $\left.86 \times 10^{2} \pm 260 \mu \mathrm{gL}^{-1}\right)$ and MCLR $\left(100 \pm 10\right.$ to $\left.24 \times 10^{2} \pm 120 \mu \mathrm{gL}^{-1}\right)$ in urine samples collected from $248 \mathrm{CKDu}$ patients in the NCP, compared to control samples (72)

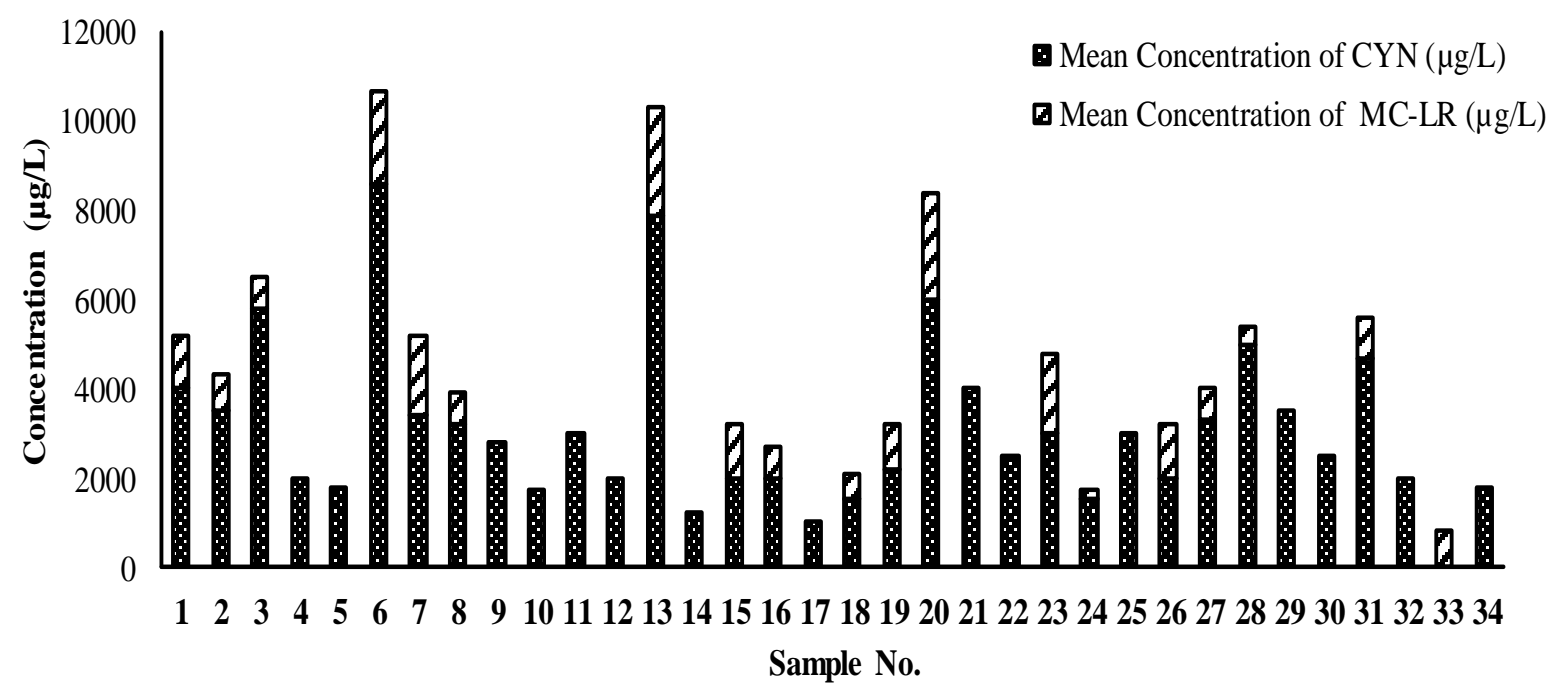

Fig 3 Mean concentrations for Cylindrospermopsin (CYN) and Microcystin-LR (MC- LR) in human urine samples in Padaviya - Bogaswewa 


\section{Pathmalal M Manage}

(below the detection limit $50 \mu \mathrm{gL}^{-1}$ ) collected from Agunukolapallassa, a non-endemic area in the Southern Province (SP). Among samples (248) However, a regular assessment of water quality is needed, and should be connected with biomonitoring (e.g. in urine) of the potential MCs and CYN and evaluate their potential health effects (Calafat 2012).

Agricultural practices, geographical characteristics, and contaminants in drinking water have been explored as likely causes for the etiology of CKDu by human biological studies, environmental studies and health mapping studies. However, although recorded data suggested that CKDu is a disease that may be caused by environmental factors, there is no conclusive study on it. Findings of Menezes et al. (2013) indicate that low doses of MC-LR induce nephrotoxic effects due to the exposure of kidneys in its toxin elimination function. The findings of a recent study of the author using normal kidney cells of a disease-free embryonic kidney indicate that MC-LR reduced significantly the survival of cells of both HEK293 and ACHN cell lines. Similarly, a significant reduction of cell viability was recorded by Alverca et al. (2009) when HEK-293 and ACHN cell lines were exposed to $30 \mathrm{mM}$ MC-LR for the same incubation period. Li and Han (2012) and Zhang et al. (2011) reported that exposure of MC-LR at 50 and $500 \mathrm{nM}$ for $24 \mathrm{~h}$ and at $10.05-$ $20.10 \mathrm{mM}$ had significantly reduced the rat Sertoli cells. Morphological analysis indicated that this cellular damage of kidneys is due to the MC-LR-induced cytotoxicity.

In conclusion, cell culture studies provide direct evidence that MC-LR exposure can induce apoptosis-related morphological changes, which are most likely to be involved in MC-LR-induced cellular damage. In-situ and in-vitro studies on accumulation MC-LR shows possible pathways to expose MC-LR via water, freshwater fish and aquatic green edible plants. It was detected that the estimated values of the MC-LR in $O$. sativa variants BG358 and Ipomea aquatica and Oreochromis niloticus were exceeded the Tolerable Daily Intake (TDI) of $0.04 \mu \mathrm{g} / \mathrm{kg}$ of body weight per day by the World Health Organization. elevated cyanotoxin concentrations Cylindrospermopsin $(\mathrm{CYN})(1.0 \pm 0.01$ to $5.3 \pm$ $\left.0.02 \mu \mathrm{gL}^{-1}\right)$ and Microcystin-LR (MC-LR) (1.0 \pm 0.01 to $\left.7.6 \pm 0.34 \mu \mathrm{gL}^{-1}\right)$ ] in commonly used dug wells show that ingestion of well water is a likely source of cyanotoxin exposure. Recent ongoing study showed that high concentration of CYN and MC-LR in urine samples collected from $\mathrm{CKDu}$ patients in the North Central Province, compared to control samples (below the detection limit $50{\mu \mathrm{gL}^{-1}}^{-}$collected from Agunukolapallassa, a non-endemic area in the Southern Province was correlated with the density of cyanobacteria, CYN and MC-LR detected in dug well which are being used for drinking purposes. The ongoing research chronic exposure of Cylindrospermopsin on Wister rat model have shown that increment of serum and urine creatine compare to the control group suggesting the chronic effect of MCs on Kidney. Future work that includes cyanotoxins as one potential risk factor in a global, multi-factorial study would help corroborate these research findings. Thus, recent studies contributed to elucidate the toxicological mechanism underlying the effects of MC-LR on the human kidney. Understanding the detailed toxicological role of MC-LR and CYN in apoptosis-related signaling pathways will require further investigations.

\section{REFERENCES}

Abeysiri, H.A.S.N. and Manage, P.M. 2017. Microsystem -LR Contamination status of Nile tilapia (Oreochromis niloticus) collected from reservoirs in Polonnaruwa District, International Research Symposium on Pure and Applied Sciences, pp. 08.

Abeysiri, H.A.S.N., Wanigasuriya, K. and Manage, P.M. 2018a. Accumulation of Cylindrospermopsin and Microcystin-LR in rice (Oryza sativa) in CKDu high prevalence Padaviya in Anuradhapura District, Sri Lanka, International Conference on Chronic Kidney Disease of Unknown Aetiology: Current Aspects and Future Prospects, pp. 28.

Abeysiri, H.A.S.N., Wanigasuriya, K. and Manage, P.M. 2018b. Cyanotoxin contamination in human urine in CKDu high prevalence Padaviya and low prevalence Rajanganaya and Galnewa in Anuradhapura District, Sri Lanka. 23rd International Forestry and Environment Symposium, pp. 210.

Alverca, E., Andrade, M., Dias, E., Sam Bento, F., Batoréu, M.C., Jordan, P., Silva, M.J .and Pereira, P. 2009. Morphological and ultrastructural effects of microcystin-LR from Microcystis aeruginosa extract on a kidney cell line, Toxicon, 54: 283-294.

Athuraliya, T.N.C., Abeysekera, D.T.D.J., Amerasinghe, P.H., Kumarasiri, P.V.R. and Dissanayake, V. 2009. Prevalence of chronic kidney disease in two tertiary care hospitals: high proportion of cases with uncertain 
Pathmalal M Manage

aetiology. Ceylon Medical Journal 54(1): Giaramida, L., Manage, P.M., Edwards, C., 345-347.

Calafat, A.M. 2012. The US National Health and Nutrition Examination Survey and human exposure to environmental chemicals. International Journal of Hygiene and Environmental Health 215(2): 99-101.

Carneiro, M., Reis, B., Azevedo, J., Campos, A., Osório, H. and Vasconcelos V. 2015. Glutathione transferases responses induced by microcystin-LR in the gills and hepatopancreas of the clam Venerupis philippinarum. Toxins. 7(6): 2096-2120.

Cazenave, J., Wunderlin, D.A., De los Ángeles Bistoni M. Amé, M.V., Krause, E. and Pflugmacher S. 2005. Uptake, tissue distribution and accumulation of microcystinRR in Corydoras paleatus, Jenynsia multidentata and Odontesthes bonariensis: a field and laboratory study. Aquatic Toxicology. 75(2): 178-190.

Chandrajith, R., Nanayakkara, S., Itai, I., Aturaliya, T.N.C., Dissanayake, C.B., Abeysekera, T., Harada, K., Watanabe, T. and Koizumi, A. 2011. Chronic kidney diseases of uncertain etiology (CKDue) in Sri Lanka: geographic distribution and environmental implications. Environmental Geochemistry and Health 33: 267-278. doi: 10.1007/s10653-010-9339-1.

Chen, J., Xie, P., Zhang, D., Ke, Z. and Yang, H. 2006. In situ studies on the bioaccumulation of microcystins in the phytoplanktivorous silver carp (Hypophthalmichthys molitrix) stocked in Lake Taihu with dense toxic Microcystis blooms. Aquaculture 261(3): 1026- 1038.

Desalegn, B,. Nanayakkara, S., Harada, K.H., Hitomi, T., Chandrajith, R., Karunaratne, U. and Koizumi, A. 2011. Mycotoxin detection in urine samples from patients with chronic kidney disease of uncertain etiology in Sri Lanka. Bulletin of Environmental Contamination and Toxicology 87(1): 6-10. doi: 10.1007/s00128-011-0301-4

Eckardt, K.U., Berns, J.S., Rocco, M.V. and Kasiske, B.L. 2009. Definition and classification of CKD: the debate should be about patient prognosis-a position statement from KDOQI and KDIGO. American Journal of Kidney Diseases 53: 915-920.

Fischer, W.J. and Dietrich, D.R. 2000. Pathological and biochemical characterization of microcystin-induced hepatopancreas and kidney damage in carp (Cyprinus carpio). Toxicology and Applied Pharmacology 164: Singh, B. and Lawton, L.A. 2013. Bacterial communities' response to microcystins exposure and nutrient availability: Linking degradation capacity to community structure. International Biodeterioration and Biodegradation 84: 111-117. http://dx.doi.org/10.1016/j.ibiod.2012.05.036

Greer, B., Meneely, J.P. and Elliott, C.T. 2018. Uptake and accumulation of Microcystin-LR based on exposure through drinking water: An animal model assessing the human health risk. Scientific Reports 8(1): 4913. doi: 10.1038/s41598-018-23312-7.

Idroos, S. and Manage, P.M. 2015. Toxin Producing Cyanobacteria in Labugama, Kalatuwawa Drinking Water Reservoirs, In: Proceedings of International Forestry and Environment Symposium, pp.20.

Idroos, S.F., Welgamage A., Manage, P.M., Edwards, C. and Lawton, L. 2014. Development of an effeciant extraction method to Quantify Microcystin-LR from Natural microcystin bloom samples from Colombo Lake Sri Lanka. Proceedings of the International Forestry and Environment Symposium 2013 of the Department of Forestry and Environmental Science, University of Sri Jayewardenepura, Sri Lanka. pp. 50. https://doi.org/10.31357/fesympo.v18i0.1 902

James, M.T., Hemmelgarn, B.R., Wiebe, N., Pannu, N., Manns, B.J., Klarenbach, S.W., Tonelli, M. and Alberta Kidney Disease Network 2010. Glomerular filtration rate, proteinuria, and the incidence and consequences of acute kidney injury: a cohort study. Lancet 376: 2096-2103. doi: 10.1016/S0140-6736(10)61271-8.

Jayasumana, C., Gunatilake, S. and Senanayake, P. 2014. Glyphosate, hard water and nephrotoxic metals: are they the culprits behind the epidemic of chronic kidney disease of unknown etiology in Sri Lanka. International Journal of Environmental Research and Public Health. 11(2): 21252147. doi: 10.3390/ijerph110202125

Jayatilake, N., Mendis, S.., Maheepala, P. and Mehta, F.R. 2013. Chronic kidney disease of uncertain aetiology: prevalence and causative factors in a developing country. BMC Nephrology 14(1): 180. https://doi.org/10.1186/1471-2369-14-180 73-81. Doi: 10.1006/taap.1999.8861 
Jos, A., Pichardo, S., Prieto, A.I., Repetto, G., Vázquez, C.M. and Moreno, I. 2005. Toxic cyanobacterial cells containing microcystins induce oxidative stress in exposed tilapia fish (Oreochromis sp.) under laboratory conditions, Aquatic Toxicology 72(3): 261-271. Doi: 10.1016/j.aquatox.2005.01.003

Jochimsen, E.M., Carmichael, W.W., An, J., Cardo, D.M., Cookson, S.T. and Azevedo, S.M. 1998. Liver failure and death after exposure to microcystins at a hemodialysi centre in Brazil. New England Journal of Medicine 338 (13): 873-878.

Lankoff, A., Carmichael, W.W., Grasman, K.A. and Yuan, M. 2004. The uptake kinetics and immunotoxic effects of microcystin-LR in human and chicken peripheral blood lymphocytes in vitro. Toxicology 204: 23-40.

Lawton, L.A., Edwards, C. and Codd, G.A. 1999. Extraction and high-performance liquid chromatographic method for the determination of microcystins in raw and treated waters, The Analyst 119: 1525-1530.

Li, Y. and Han, X.D. 2012. Microcystin-LR causes cytotoxicity effects in rat testicular Sertoli cells. Environmental Toxicology and Pharmacology 33: 318-326.

Liang, X.F., Li, G.G., He, S. and Huang, Y. 2007. Transcriptional responses of alpha- and rho- class glutathione S- transferase genes in the liver of three freshwater fishes intraperitoneally injected with microcystin- LR: Relationship of inducible expression and tolerance. Journal of Biochemical and Molecular Toxicology 21(5): 289-298.

Malbrouck, C., Trausch G., Devos, P. and Kestemont, P. 2003. Hepatic accumulation and effects of microcystin-LR on juvenile goldfish Carassius auratus L. Comparative Biochemistry and Physiology Part C, Toxicology and Pharmacology 135(1): 39-48.

Manage, P.M., Edwards, C., Singh, B.K. and Lawton, L.A. 2009. Isolation and identification of novel microcystin-degrading bacteria. Applied Environtal Microbiology 75(21): 6924-6928.

Manage, P.M., Kawabata, Z.I. and Nakano, S.I. 1999. Seasonal changes in densities of cyanophage infectious to Microcystis aeruginosa in a hypereutrophic pond. Hydrobiologia 411: 211-216.

Manage, P.M., Edwards, C. and Lawton, L. 2010. Bacterial degradation of microcystin. pp. 97-104. In: N.
Hamamura, S. Suzuki, S. Mendo, C. M. Barroso, H. Iwata and S. Tanabe (eds) Interdisciplinary studies on environmental chemistry - Biological responses to contaminants. TERRAPUB, Tokyo.

Manage, P.M. 2012. Study on algal and cyanobacteria identification, species composition, determination of concentrations of N, P, Mn, Fe, COD, TOC (Total Organic Carbon) and screening of hepatotoxin Microcystin-LR in some selected drinking and irrigation water bodies in Sri Lanka. Final report submitted to National Water Supply and Drainage Board.

Menezes, C., Valério, E. and Dias, E. 2013. The kidney Vero-E6 cell line: a suitable model to study the toxicity of microcystins. pp. 29-48. In: New Insights into Toxicity and Drug Testing, Chapter 2. https://www.intechopen.com/books/newinsights-into-toxicity-and-drug-testing/thekidney-vero-e6-cell-line-a-suitable-model-tostudy-the-toxicity-of-microcystins. doi: 10.5772/54463. [26 January 2019].

Nogueira, I.C., Lobo-da-Cunha, A. and Vasconcelos, V.M. 2006. Effects of Cylindrospermopsis raciborskii and Aphanizomenon ovalisporum (cyanobacteria) ingestion on Daphnia magna midgut and associated diverticula epithelium. Aquatic Toxicology 80(2): 194-203.

Paerl, H.W. and Huisman, J. 2008. Blooms like it hot. Science 320: 57-58.

Piyathilaka, M.A.P.C., Manage, P.M., Tennekoon, K.H., De Silva, B.G.D.N.K., Samarakoon, S.R. and Chanthirika, S. 2015. Microcystin-LR-induced cytotoxicity and apoptosis in human embryonic kidney and human kidney adenocarcinoma cell lines. Microbiology 161: 819-828

Sethunga. H. and Manage, P.M. 2010. Contamination status of algae toxins microcystins in some selected water bodies in Sri Lanka, International Environmental Symposium, pp. 25.

Wanigasuriya, K. 2012. Aetiological factors of chronic kidney disease in the North Central Province of Sri Lanka: A review of evidence to-date. Journal of the College of Community Physicians of Sri Lanka 17(1): 21-42. DOI: http://doi.org/10.4038/jccpsl.v17i1.4931

Wanigasuriya, K.P., Peiris-John, R.J., Wickremasinghe, R. and Hittarage, A. 2007. Chronic renal failure in North Central Province of Sri Lanka: an environmentally induced disease. Transactions of the Royal 
Pathmalal M Manage

Society of Tropical Medicine and Hygiene 101(10): 1013-1017.

Wasana, H.M., Perera, G.D., Gunawardena, P.D.S., Fernando, P.S. and Bandara, J. 2017. WHO water quality standards Vs Synergic effect (s) of fluoride, heavy metals and hardness in drinking water on kidney tissues. Scientific Reports 7: 42516. doi: 10.1038/srep42516.

WHO 1998, Guidelines for Drinking Water Quality, 2nd edn. Addendum to Volume 2, Health Criteria and other supporting information. Geneva: Guidelines for Drinking Water Quality, 3rd edn. Incorporating the First and Second Addenda, Recommendations. World Health Organization, Geneva.

WHO 2012, Chronic Kidney Disease of Unknown Origin (CKDu), Available from: <www.whosrilanka.org>. [19 November 2014].

Wijerathne, P.K.D.K.B. and Manage, P.M. 2018. Accumulation status of Microcystin-LR in cultured and natural samples of Oreochromis niloticus (Nile Tilapia). Journal of Entomology and Zoology Studies 6(4): 10221026.
Wijetunge, S., Ratnatunga, N.V.I., Abeysekera, D.T.D.J., Wazil, A.W.M., Selvarajah, M. and Ratnatunga, C.N. 2013. Retrospective analysis of renal histology in asymptomatic patients with probable chronic kidney disease of unknown aetiology in Sri Lanka. Ceylon Medical Journal 58(4): 26-29.

Wijewickrama, G.M.M.K. and Manage, P.M. 2017. Accumulation status of MC-LR in Ipomoea aquatica plant tissues. Proceeding of the $4^{\text {th }}$ International Conference on Multidisciplinary Approaches, pp. 159.

Wimalawansa, S.J. 2016. The role of ions, heavy metals, fluoride, and agrochemicals: critical evaluation of potential aetiological factors of chronic kidney disease of multifactorial origin (CKDmfo/CKDu) and recommendations for its eradication.Environmental Geochemistry and Health 38(3): 639-678.

Zhang, H.Z., Zhang, F.Q., Li, C.F., Yi, D., Fu, X.L. and Cui, L.X. 2011. A cyanobacterial toxin, microcystin-LR, induces apoptosis of sertoli cells by changing the expression levels of apoptosis-related proteins. Tohoku Journal of Experimental Medicine 224(3): 235-42. doi: $10.1620 /$ tjem.224.235. 